\title{
Involving people with intellectual disabilities within research teams: Lessons learned from an Irish experience
}

Corresponding author:

Edurne García Iriarte

National Institute for Intellectual Disability, Trinity College Dublin, Dublin, Ireland

3 College Green $4^{\text {th }}$ Floor

Dublin 2

Ireland

Email: iriartee@tcd.ie

Phone: +353 I 8962200

Co-authors:

Patricia O'Brien

Centre for Developmental Disabilities Studies, University of Sydney, Sydney, Australia

Darren Chadwick

University of Wolverhampton, Wolverhampton, England

Key words: intellectual disabilities, research, feasibility, knowledge, change

Running Head: People with intellectual disabilities in research teams

Author's note: This research was funded by a Marie Curie Transfer of Knowledge Fellowship to the National Institute for Intellectual Disability, Trinity College Dublin, within the $6^{\text {th }}$ European Community Framework Programme. The views expressed herein are those of the authors and not necessarily those of the $6^{\text {th }}$ European Community Framework Programme.

Citation: Iriarte Garcia, E., O’Brien, P. \& Chadwick, D.D. (20I4). Involving People With Intellectual Disabilities Within Research Teams: Lessons Learned from an Irish Experience. Journal of Policy \& Practice in Intellectual Disabilities, II (2), I49-I 57.

DOI: 10.1 I I I/jppi. I208I 


\begin{abstract}
Background: A growing body of literature has shed light into the process of conducting research with people with intellectual disabilities. However, there is limited research on the feasibility of conducting research projects including various groups of people with intellectual disabilities, their supporters and researchers. Specific Aims: This paper reviews three studies conducted with these three groups of people in light of their feasibility, the knowledge generated, and their impact on individual and social change. Method: This study used a reflective analysis focused on the main findings from the three studies, focus groups with people with intellectual disabilities and supporters who conducted the research, and interviews with people to whom the findings were disseminated. Findings: The analysis suggested that a team approach including active supporters and experienced researchers was critical to their feasibility. The studies generated knowledge particularly on the perspectives of people with intellectual disabilities on their rights. As a result of participation in these studies, some changes at the individual and social levels occurred but these were relatively limited. Discussion: The implications of this analysis for future research are discussed in the context of the implementation of the United Nations Convention on the Rights of Persons with Disabilities.
\end{abstract}




\section{Introduction}

Involving people with intellectual disabilities within research teams: Lessons learned from an Irish experience In the past two decades, approaches to disability research that include people with disabilities as part of the research team (e.g., emancipatory and inclusive) have gained recognition in the academic literature, research funding agencies, and policy documents (Priestley, Waddington, \& Bessozi, 20I0; Townsend, 20II). The reasons behind the participation of people with disabilities as part of the research team include (i) epistemological: to provide an insider perspective to better appraise the phenomenon under examination (Turnbull \& Turnbull, 1994); (ii) political: to ensure people with disabilities are in control of the research design, process, and dissemination;

and (iii) action-oriented: to effect social and political change (Barnes, 2006; Oliver, 1992; Zarb, 1992). Beyond these reasons, research conducted ethically has provided further opportunities to people with disabilities to equally engage as participants in research projects (NDA, 2009)

Research with people with intellectual disabilities has generated a substantial amount of academic literature. Walmsley and Johnson (2003) termed this type of research "inclusive research" and described it as research where people with disabilities have valued social roles and gain knowledge on issues important to them. According to Walmsley and Johnson, inclusive research is where the research activity furthers the interests of people with intellectual disabilities, is accessible to them and collaborative, and where they are able to exert some control over the process and its outcomes. Examples exist in the literature of studies that have included people with intellectual disabilities in the identification of research questions (Garbutt, Tattersall, Dunn, \& Boycott-Garnett, 
2009), data collection and analysis (Kramer, Kramer, Garcia-Iriarte, \& Hammel, 2010;

Tuffrey-Wijne \& Butler, 2009), reflection (Bigby \& Frawley, 2010), and dissemination of research findings (Goodley \& Moore, 2000; Wyre Forest Self-Advocacy \& Tarleton, 2005). These studies have greatly contributed to the methodological knowledge on how to include people with intellectual disabilities in research. It should be noted, however, that they mostly included one already existing group of people with intellectual disabilities (e.g., a self-advocacy group). Research conducted with people with intellectual disabilities, however, is associated with major tensions regarding their involvement in the research process, power to make decisions about the research, ownership of the research process and outcomes, emphasis on divisions between disabled and non-disabled researchers, and more practical issues such as producing accessible versus non-accessible formats (Abell et al., 2007; Bigby \& Frawley, 2010; Dowse, 2009; Gilbert 2004; Goodley \& Moore, 2000; Kellett, 2010; Walmsley, 200I). These tensions are even more relevant when different groups of people with intellectual disabilities, supporters, and university researchers are involved.

Research projects conducted with people with intellectual disabilities take on a particular importance in the context of the United Nations Convention on the Rights of Persons with Disabilities (CRPD) (UN, 2006). Under Article 3I of the CRPD, States are required to collect disaggregated information on the barriers faced by persons with disabilities in exercising their rights. There have been, however, very few studies conducted about the perspectives of people with intellectual disabilities on their rights at the State level. These include the studies by Emerson, Malam, Davies, and Spencer (2005) in England, Logan et al. (2003) in New Zealand, Curtice (2006) in Scotland, and the Association for Self-Advocacy in Croatia (2007). Of these, only the Emerson et al. study 
and the Croatian study included people with intellectual disabilities as part of the research team. The details on the procedures to conduct these studies with the participation of people with intellectual disabilities have not been fully documented in the literature.

While the feasibility of research conducted with people with intellectual disabilities has captured much attention, the impact of research conducted with people with intellectual disabilities and the knowledge generated are also critical parameters of this type of research (Barnes, 2006; Barton, 2005; Goodley \& Moore, 2000; Walmsley, 200 I; Walmsley \& Johnson, 2003; Zarb, 1992). Turnbull and Turnbull (1994) already argued in relation to participatory research that such an approach is a means to new knowledge, not an end in itself. For example, Johnson (2009) concluded that inclusive research conducted in Ireland helped people with intellectual disabilities become better self-advocates. However, few studies have focused on the research products and accountability of research to people with intellectual disabilities from a reflective standpoint (McBeth, 2010).

Townsend (20II) provides a useful model to analyse impact of research at different levels at either individual (i.e., quality of life, satisfaction with access and interventions, and functional status) and or social (i.e., changes in the social environment, relationships or functioning between the individual and the environment which can be produced as a result of policy or service developments) levels. However, the analysis of impact needs to be cautiously approached as the relationship between research and policy, for example, is neither direct nor linear and is mediated by a range of factors such as resources, tradition, media, and lobbying (Hegarty, 1997).

In summary, there has been limited systematic analysis regarding the contribution of research to a better understanding of the lived experiences and perspectives of people 
with intellectual disabilities and the influence that such research can have on policy, practice, and social change. It is therefore the purpose of this paper to reflect on these gaps and contribute to the debate on the basis of three studies conducted with various groups of people with intellectual disabilities, their supporters and university researchers. Specifically, the questions this paper seeks to answer are: (i) How feasible is it to conduct research with people with intellectual disabilities involving various groups of people, researchers and supporters?; (ii) In what ways does research conducted with people with intellectual disabilities generate knowledge?; and (iii) How does research conducted with people with intellectual disabilities have an impact at individual and social levels? 


\section{Method}

Context. The National Institute for Intellectual Disability (NIID) received European research funding to conduct a survey of people with intellectual disabilities in Ireland which resulted in the All We Want to Say study (NIID, 2009, 20I0). A secondary aim of the grant was to develop an Irish Inclusive Research Network (IRN) in association with a national umbrella organisation of services for people with intellectual disabilities. The IRN conducted two additional research studies: the Where We Live (IRN, 2009) and the Relationships and Supports (IRN, 20I0).

The research process followed in the three projects is summarised in Table I. The roles of researchers with intellectual disabilities, university researchers, and supporters are outlined for each project on the research phases from identification of the research topic to dissemination of findings and follow-up action (see Table I). Detailed descriptions of how these projects were conducted are available in the projects' main reports (IRN, 2009, 20I0; NIID, 2009, 20I0).

Participants. Between the three studies, there were $4 \mathrm{I}$ researchers with intellectual disabilities, 24 supporters and II university researchers conducting the research. The term "university researchers" was suggested by researchers with intellectual disabilities to differentiate researchers with intellectual disabilities from those who did not have them and were based either at a university or at an organisation. Researchers with intellectual disabilities were recruited by university researchers through self-advocacy organisations, research groups of people with intellectual disabilities, and service organisations, some of whom became members of the emerging IRN. The researchers with intellectual disabilities were supported by paid staff already known to them, such as self-advocacy group 
supporters and support workers in day services, family members and peers with more research experience.

Analysis. The reflective analysis involved collation and synthesis of data from the three studies including: (i) main study findings; (ii) data from two focus groups conducted respectively with ten out of $4 \mathrm{I}$ researchers with intellectual disabilities and with four out of 24 supporters to evaluate their participation in the research process (NIID, 20I0); and (iii) I4 interviews conducted with people external to the research process who attended presentations of the All We Want to Say findings (NIID, 20I0). All focus groups participants had been part of the research team in the All We Want to Say Study. Of the researchers with intellectual disabilities who took part in the focus groups, two had been part of the research team in all three studies, three in two of them, and five only in the All We Want to Say study. Two of the supporters in the focus group had been part of the research team in the three studies, one of them in two studies and the fourth supporter only in the All We Want to Say study. Two of the authors were part of the research team in the three studies and one of them in two studies. The authors, who were university researchers, conducted this critical reflection based on a thematic analysis through axial coding of the focus groups and interviews around three parameters, namely, feasibility of the project, knowledge generation, and change at individual and social levels. Preliminary conclusions were reached and subsequently reviewed by the authors which resulted in the critical reflection presented below. The conclusions refer overall to feasibility and change within three studies. The focus groups were conducted when the All We Want to Say and the Where We Live studies had been completed and the Relationships and Supports study was having its data analysed. 
Table I Research Process

\begin{tabular}{|c|c|c|c|}
\hline & All We Want to Say & Where We Live & Relationships and Supports \\
\hline \multicolumn{4}{|c|}{ Identification of topic } \\
\hline Who & Committee* & $\begin{array}{l}\text { IRN members with } \\
\text { intellectual disabilities }\end{array}$ & IRN members with intellectual disabilities \\
\hline Topic & Life in Ireland & Living options & Relationships and supports \\
\hline Process & \multicolumn{3}{|c|}{ Discussion facilitated by university researchers (URs) } \\
\hline \multicolumn{4}{|c|}{ Identification of method } \\
\hline Who & Committee & $\begin{array}{l}\text { IRN members with } \\
\text { intellectual disabilities }\end{array}$ & IRN members with intellectual disabilities \\
\hline Method & Focus groups & Survey & Focus groups \\
\hline Process & Discussion facilitated by UR & & Consultation facilitated by UR \\
\hline Sample & 168 & 43 & 97 \\
\hline Ethical approval & \multicolumn{3}{|c|}{ UR applied for and obtained ethical approval } \\
\hline $\begin{array}{l}\text { Accessible } \\
\text { materials }\end{array}$ & \multicolumn{3}{|c|}{ UR and people with intellectual disabilities developed accessible materials } \\
\hline $\begin{array}{l}\text { Recruitment of } \\
\text { research team } \\
\text { (RT)** }\end{array}$ & \multicolumn{3}{|c|}{$\begin{array}{l}\text { UR recruited researchers with intellectual disabilities and supporters from self-advocacy groups, existing } \\
\text { research groups, and services. }\end{array}$} \\
\hline Training & \multicolumn{3}{|c|}{ UR facilitated research training workshops for researchers with intellectual disabilities and supporters } \\
\hline $\begin{array}{l}\text { Recruitment of } \\
\text { participants }\end{array}$ & Research team (RT) & \multicolumn{2}{|c|}{ Researchers with intellectual disabilities and supporters } \\
\hline Data collection & Research team (RT) & \multicolumn{2}{|c|}{ Researchers with intellectual disabilities and supporters } \\
\hline Data analysis & \multicolumn{3}{|c|}{$\begin{array}{l}\text { I. UR did preliminary analyses of qualitative/quantitative data } \\
\text { 2. RT came together to interpret the data }\end{array}$} \\
\hline \multirow{2}{*}{$\begin{array}{l}\text { Dissemination of } \\
\text { findings }\end{array}$} & \multicolumn{3}{|c|}{ Reports and conferences (RT) } \\
\hline & DVD (RT) & No & No \\
\hline Follow up action & $\begin{array}{l}\text { Presentations (RT) } \\
\text { Community committees }\end{array}$ & No & $\begin{array}{l}\text { Presentations to the Law Reform commission } \\
\text { in the Republic of Ireland (Researchers with } \\
\text { intellectual disabilities and their supporters) }\end{array}$ \\
\hline
\end{tabular}




\section{Results}

Feasibility

These three research studies were feasible because researchers with intellectual disabilities were interested in the topics and worked throughout the different phases of the studies supported by university researchers and supporters. The work was undertaken by local teams of researchers with intellectual disabilities and supporters, and coordinated nationally by university researchers.

The contribution of university researchers. University researchers took on a training and coordination role, organising workshops in order to build the research teams and provide some basic understanding of research methods. University researchers applied for and secured university ethical approval, provided research tools for data collection and analysis, and facilitated the development of accessible materials (Ward \& Townsley, 2005) and report writing (see Table I). This coordination role included reminding the individual research teams about next steps to progress the research studies and deadlines, and checking on the additional support needed by the individual research teams to conduct the research studies. Some of the local teams identified gaps in their research knowledge and skills which required additional support. In those cases where further training was required, university researchers provided additional support to address contextual needs that varied between groups. As one supporter noted: "We found the most useful of all was the individual (...) day that we met up with [university researcher] here ourselves, it was just our group (...) it really gave us a chance (...) it was very encouraging to know that we were on the right track and it made us kind of focus more on the goal side of things."

University researchers relied on e-mail communication with supporters to follow up with the groups of researchers with intellectual disabilities. Ideally, university 
researchers would have communicated directly with researchers with intellectual disabilities. However, scarcity of resources on both parts limited this communication. Firstly, researchers with intellectual disabilities experienced restrictions in the use of phones. Secondly, e-mail was not an option for researchers with intellectual disabilities who had limited literacy skills and lacked both computer skills and access to computers. Follow up about specific problems or needs (e.g., equipment, need for more training/clarification, further ethical approval) originated from individual groups of researchers with intellectual disabilities, mainly through their supporters.

The involvement of university researchers with their peers with intellectual disabilities and their supporters facilitated the approval of the latter's Chief Executive Officers (CEOs) to their involvement in research. As stated by one of the supporters, "It tied into the work that we were doing here, and we wanted to be more involved (...) the fact that we were taken seriously on a national level by [University] with lots of CEOs giving approval to what was going on helped to open that door a bit wider."

The contribution of researchers with intellectual disabilities. The researchers with intellectual disabilities participated in the identification of topics of personal interest to them: namely, relationships and living independently (see Table I). They recruited participants, collected data, participated in data analysis, report writing, and dissemination of findings. They valued their participation in the research projects and felt it was an opportunity that other people with intellectual disabilities would enjoy and should access. For example, one of the researchers with intellectual disabilities said, reflecting on the value of being part of the research: "And there's a lot of people that could be here." Another researcher with an intellectual disability commented on the limitations faced by them to take part: "They would like to be here but they can't be." 
The work of researchers with intellectual disabilities throughout the research phases was apparent to supporters, in one case, keeping one of them on top of the support she provided: "The co-researcher (...) kept a check on me (...) he would ring down and [asked] 'when are we going in again' and constantly (...) reminding (...) 'what is next?' and you really have to keep on your toes."

The contribution of research supporters. All supporters self-selected to participate in the project and were aligned with the aims of self-advocacy. Some of them were already members of the local teams and some were identified by the researchers with intellectual disabilities. They facilitated communication with university researchers, made arrangements with service personnel, and provided support to researchers with intellectual disabilities to attend the research meetings and conduct the research studies.

The role of the supporter was crucial in keeping researchers with intellectual disabilities abreast of the research process and bridging the gap of accessibility. Although all the written materials included pictures and single-idea sentences, and were piloted by people with intellectual disabilities (Ward \& Townsley, 2005), they were not universally accessible. Therefore, supporters also helped by explaining the information about the process or in the handbooks that were developed for researchers with intellectual disabilities. As one supporter noted: "As supporters (...) explaining things in different ways so that they did get an understanding."

Supporters worked alongside researchers with intellectual disabilities in the recruitment of research participants, data collection, data analysis and dissemination of findings (see Table I). For example, they helped them ensure that everyone had understood and signed the consent forms and the audio recording equipment worked in the focus groups, and they asked questions that facilitated researchers with intellectual 
disabilities to reach conclusions based on the findings.

Despite researchers with intellectual disabilities and supporters liaising with the service organisations, a major limitation to providing support arose when these organisations failed to recognise the importance of the research studies and the role supporters played in facilitating the research process. This lack of organisational recognition of research, in turn, resulted in the organisations' failure to provide supporters with adequate resources and time to carry out their research supporter role fully. This led to researchers with intellectual disabilities being unable to attend research meetings, delays in organising and conducting the data collection, and, in some instances, withdrawal from the project. In fact, researchers with intellectual disabilities who joined the projects with no supporter dropped out. In the words of one researcher with an intellectual disability, the importance of supporters in conducting the research projects could not be overstated, "Maybe to let managers know what we've had [research projects] then the organisation (...) could give us support as well. So they could let the staff know (...) that the research was going on so that the management will put on someone else in place if your supporter got very sick (...) for several weeks."

Team approach. The work for the three research projects followed a team approach. At a local level, groups of researchers with intellectual disabilities and their supporters came together and provided mutual support to individual members of the group. For example, researchers with intellectual disabilities who had reading skills read out loud and explained materials to other members of the group. These groups then all came together with the university researchers in one-day events. The groups and their members differed in their research knowledge, skills, and prior experience of conducting research. In this context, a team approach proved to be very useful as different groups collaborated with each other 
and shared their skills and ideas.

During the training workshops for the three research studies people developed social relationships and a sense of belonging to a wider research team. This can be illustrated by the following quote by one researcher with an intellectual disability: "We made more friends." The words of a supporter also concurred with the above: "We were building up to something definitely (...) when the DVD was made, and subsequently the main presentation (...) really feeling that they were part of something that was happening on a nationwide basis."

A team approach was also critical in the fieldwork, which required researchers with intellectual disabilities and supporters to work independently of university researchers in recruiting people, collecting, and analysing the data (see Table I). However, not all the teams succeeded in conducting the research projects, and a lack of teamwork was the reason for one of the groups dropping out during the All We Want to Say study. Meetings with all the local teams also proved difficult because of travel challenges for local groups dispersed across Ireland and the fact that the two main organisations of university researchers were in cities in the East and the West of Ireland.

In summary, the key success factors to conduct the three research projects were: the interest and persistence of researchers with intellectual disabilities; a team approach to the research projects adopted by all the people involved; research support around research training, receptive understanding, expressive communication and travel provided by the supporters; and research coordination by university researchers. The main challenges were lack of organisational support, difficulty in attending meetings due to travel issues, and failure to work in teams in one of the groups of researchers with intellectual disabilities. 
Knowledge

Including people with intellectual disabilities in the research process led to the generation of new findings that have enhanced our knowledge of the lived experiences of people with intellectual disabilities in Ireland. In particular, how the latter felt about aspects of their lives, their aspirations and their awareness of, and desire for, the exercise of their rights. Including them in decisions about which areas to study and what research questions to ask also increased the relevance of the research to them. Although these areas have been investigated in earlier studies, they seldom included the perspectives of people with intellectual disabilities as the focus of the research. The three studies referred to here were the first studies in Ireland to include people with intellectual disabilities as integral members of the research teams to examine the perspectives and experiences of their peers in relation to employment, relationships, education, health, social life, and living situation (NIID, 2009), privacy and independence, choice, satisfaction with living situation, and transportation (IRN, 2009), and friendships, relationships, and supports (IRN, 20I0). By reference to each of the studies, we next illustrate how the participation of people with intellectual disabilities in the research team resulted in relevant questions and an authentic capture of their lived experience.

The All We Want to Say (NIID, 20I0) highlighted that the needs of people with intellectual disabilities go beyond support and medical care; people with intellectual disabilities are active citizens of society with a critical perspective on the supports they receive and can identify barriers to the exercise of their rights as citizens: "Well l'd like to see just people's attitudes change, (...) that we have rights like everybody else and just try get people more involved in decisions about their lives" (Study participant). There was frustration too at the difficulty in changing anything in their lives: "l've been having a social worker for 
three years and I haven't changed anything [to] the way I want it to be" (Study participant). This frustration around lack of control extended to their experience of basic health care: "And another thing is (...) knowing what you are [taking], being able to say we would rather take this medication (...) control of your own medication" (Study participant).

The Where We Live (IRN, 2009) highlighted people's aspirations for their living situation and the limited choice people with intellectual disabilities had in deciding where and with whom they lived: "It might be nice down the line to get a housemate but it would only be good if I owned the house and could choose who I live with" (Study participant). The study also revealed what supports people with intellectual disabilities wanted in order to live their lives: support to go out, to work, to look after the house, and a range of different staff providing this support.

Relationships were addressed in both the All We Want to Say and the Relationships and Supports studies. The latter corroborated previous findings regarding relationships in Ireland in that adults with intellectual disabilities were aware of their rights to have relationships, saw relationships as a source of support, and perceived that sexual relationships were prohibited in services (Healy, McGuire, Evans, \& Carley, 2009; Kelly, Crowley, \& Hamilton, 2009). However, the Relationships and Supports study additionally identified that people with intellectual disabilities: i) saw friendships as a source of support; ii) wanted staff and family support to maintain relationships; and iii) were sometimes confused about the difference between friendships and relationships.

The desire for choice and control was of paramount importance to the people with intellectual disabilities who participated in the three studies; it was a theme of its own in the All We Want to Say study and was a cross-cutting theme in all three studies. One of the study participants said "I want to be able to travel around the world, to have friends around 
me and do all that and then say 'right I want to settle down and have a fellow and then decide right I want to have kids."”

Past attempts to capture the experiences of people living with intellectual disabilities in Ireland have been through non-systematic consultation (see National Federation of Voluntary Bodies, 2007) or aggregated in combination with people with other disabilities (see NDA, 2004) but without involving people with intellectual disabilities as integral research team members. While these studies contribute to the knowledge we have in Ireland today about services, policies, and participation of people with intellectual disabilities in the community, the inclusion of researchers with intellectual disabilities in the research team allowed the identification of research questions and the design of relevant data collection instruments which generated a rich and authentic account of their perspectives and their lived experiences.

\section{Change}

While involvement in this type of research produced change at different levels, it was limited. In accord with prior literature which has described the limited causal link between research and social and political change, the research findings did not appear to lead on to wider social changes. Researchers with intellectual disabilities and supporters tended to refer to the impact of conducting research at personal and community levels and identified the lack of impact at a more macro level, including organisational, societal and political, and indicated how the barriers to changes at these wider levels could be addressed.

Individual level. When talking about change, supporters focused on the benefits that the research had on the groups of researchers with intellectual disabilities. Comments focused on credibility gains, but growth in personal confidence, respect, self-esteem, and 
personal improvement were also mentioned. One of the audience members in the presentation of the All We Want to Say study results (see Table I) noted growth in selfconfidence of one of the researcher with an intellectual disability: "The challenge for her [was] to speak in front of a senior manager in her organisation and I was struck by the speed and force by which she came to the challenge."

Regardless of personal gains, researchers with intellectual disabilities pointed to the lack of additional benefits that research could have for them compared to the far greater benefits to university researchers (e.g., employment, career advancement). According to one of them, research could become a paid job for people with intellectual disabilities: "That if the research does stop here, that it won't stop in other places, that it will keep going, and that one day, people with disabilities could be paid researchers" (Researcher with an intellectual disability). Other individual impacts in quality of life or satisfaction with access and interventions which have been identified in previous literature (e.g. Townsend, 20I I) were not mentioned.

Social level. The communities in which the research findings were presented gained increased awareness of the research work that people with intellectual disabilities performed and their needs and wishes identified by the research. For example, a person with an intellectual disability in the audience said: "I didn't think people like myself could do something like that." And a manager in the audience noted: "The disability sector and especially the intellectual disability sector can often find itself at the bottom of the pile in terms of its activism and in terms (...) for getting real change and I think this content is really useful and (...) good."

Researchers with intellectual disabilities talked about the impact the presentations had on managers, families, and the media. A researcher with an intellectual disability 
noted: "It was good that management was there to see the work that we did because a lot of people think (...) that you didn't really do [it]." Another researcher with an intellectual disability said: "Tell them about how people from the [local paper] was there and how we got the photograph in the paper."

Researchers with intellectual disabilities and supporters experienced frustration at the end of the research projects when there was no evident change in their lives, and the research activity had stopped. A researcher with an intellectual disability noted in a focus group: "Do you know, even though we are involved in this research, some things for some people may not change, [kinda] [sic] we are not going to change (sighs)." Linked with the above discussion, supporters pointed to unrealistic expectations of change. When the funding for the projects ended and the university researchers were no longer available to provide formal support to the groups, researchers with intellectual disabilities and supporters identified lack of coordination as an issue to take action: "I'm not sure what's going to happen because l'm not sure who is going to co-ordinate (...) I'm not sure if that's workable really" (Supporter).

The impact that the research studies had from the perspective of researchers with intellectual disabilities can be illustrated in the following quote by one of them, "Now that it's done what's going to happen to it now, is it going to be shown to people or are we going to do the next stage to it (...)?. Well you see it's OK to be doing research but we would like to see some results."

Researchers with intellectual disabilities were able to identify how organisational change could be facilitated through education and use of media. One of them said: "What is it about the research, the relationships, I would like to see the [organisation] changing their mind towards people having relationships within the organisation." They identified the media as 
critical to get their word out and produce change. Another researcher with an intellectual disability said: "Do the drama, go on [TV] [sic], put that on [TV] [sic] and then everybody listen[s] [sic]."

After the Relationships and Supports study report was published, the IRN was invited to take part in the consultation process of the Law Reform Commission in Ireland for the Criminal Justice (Sexual Offences) Act of 1993. Participation at the level of consultation in the law reform shows how research conducted with people with intellectual disabilities legitimised a unique perspective and provided the opportunity to take part in the process of changing legislation which was at the core of the ratification of the CRPD in Ireland in $201 \mathrm{I}$. 


\section{Discussion}

The CRPD is likely to be central in the review and development of disability policy for the signatory countries in the coming years (Clifford, 20I I). At the time when this manuscript was being written, I53 States had signed the CRPD and II 4 had ratified it, 90 had signed the optional protocol and 65 ratified it (UN, 2012). Research that involves people with disabilities becomes crucial to accomplish this endeavour. Within this context, conclusions on the benefits and challenges of conducting research with people with intellectual disabilities are next presented.

The authors' experience in these three studies concurs with Walmsley's (200I) view in that, where research with people with intellectual disabilities is concerned, people with intellectual disabilities, supporters, and university researchers together can share control over the research process in a meaningful way. This paper has provided evidence of the value of including people with intellectual disabilities in the research team in terms of knowledge generation and individual and social impact.

However, on completion of the research projects, despite the possible gains for the researchers with intellectual disabilities, their concrete situation in terms of their daily lives, their relationships and friendships, and their living arrangements was perceived by them to be the same as at the beginning of the research. Similar to other participatory approaches, there are intrinsic risks involved in carrying out this type of research (Turnbull \& Turnbull, 1994). It is dangerous to adopt an uncritical acceptance of the inherent benefits of inclusive approaches. Consideration of the potential harm well meaning researchers may do by setting expectations for researchers with intellectual disabilities that their involvement in research will inevitably lead to positive change in their lives is necessary (e.g., in terms of life opportunities, service developments and career opportunities as a paid researcher). It is 
possible that, although the inclusive research activity described in this study may energise people for a while, regrettably, it is likely that this energy will not be maintained without additional input. This raises questions as to how such energy can be maintained and mobilised towards desired change.

This finding suggests that more time and funding as well as continuous evaluation of the research outcomes are needed to complete and follow up on action to effect change. Research aims that directly target solutions to the challenges that people with intellectual disabilities face would also be appropriate (Turnbull \& Turnbull, 1994). Furthermore, support in the areas of leadership and dissemination to wider audiences are needed in order to use the research results to effect social change. Researchers with intellectual disabilities and supporters identified university researchers as having this leadership role because they had coordinated the research part and provided credibility to the process. However, advocacy strategies become more important at this stage than the expertise university researchers can contribute. Thus, research projects aiming at social change need to incorporate a step between obtaining the research results and effecting change. This will make it possible to explore, firstly, whether further action beyond the dissemination and setting goals can lead to social change and, secondly, whether the experiences of people with intellectual disabilities improve as a result. As has been noted, research is only one strand of influence on policy (Barnes, 2006; Hegarty, 1997).

While there is value in the involvement of people with intellectual disabilities in research for political and epistemological reasons, people with intellectual disabilities experienced frustration when the research results did not directly affect expected changes. The way in which research funders often operate does not lend itself to continued support once the research project ends, nor is it likely funding bodies will 
increase funding for extended roll out, dissemination and subsequent development activities. Moreover, it remains unclear how the 'bottom-up' information gathered from inclusive research can be used to transform bureaucratic, traditionally 'top-down' organisations. A question that needs further consideration is how to build an appropriate end point into inclusive research studies in such a way that all parties feel satisfied with the study outcomes and experience a sense of 'closure' for the project.

The CRPD, however, may offer a different framework for action as it requires States to collect disaggregated data "to help assess the implementation of States Parties' obligations under the present Convention and to identify and address the barriers faced by persons with disabilities in exercising their rights" (UN, 2006). If research is commissioned to monitor the implementation of policies and the exercise of human rights by people with disabilities, action may happen as a result of it. Funding and commitment from management of organisations and politicians become critical. Firstly, funding agencies need to plan for an action phase that allows research teams to establish collaborations with relevant stakeholders that can implement change based on the research findings. Secondly, research teams need to convince decision makers of the value and legitimacy of the research enterprise in order to increase the likelihood of implementing those changes. This type of research will provide disabled people, organisations representing them, and their allies with valuable information to monitor the implementation of the CRPD in their own countries and holding their governments accountable for it.

The three studies analysed in this paper were conducted in the context of European Union funding within an applied social research approach involving face-to-face data collection methodologies with focus on the rights of people with intellectual disabilities and in a specific country, Ireland, with particular geographical, political, and 
social characteristics. Our data only allows us to comment in an informed way in this type of research and the conclusions of the paper should be applied cautiously to other research approaches and research areas. People with intellectual disabilities could feasibly be involved in other types of research but the issues that arise may differ, for example, risk, safety, accessibility of abstract concepts, the properties of materials, and use of expensive specialised equipment that may be used in more natural science. Other research with more indirect relationship with people's lives may be of less interest to people with intellectual disabilities.

How people with complex support needs, including those with profound and multiple disabilities, can be involved in research endeavours has yet to be considered. This is a critical focus for ongoing investigation and reflection in this area. Further research needs to be conducted to empirically examine the long-term impact of research conducted with people with intellectual disabilities at individual and social levels. The framework for analysis used in this article, could be systematically applied to other studies conducted within participatory and emancipatory research frameworks. Such would build an empirical evidence base for consideration by funding bodies on the value of this type of research in terms of its feasibility, knowledge generated and change produced or promoted.

Acknowledgements. The authors are indebted to researchers with intellectual disabilities and supporters who participated in the different studies, NIID and National Federation of Voluntary Bodies staff, Profs. Roy McConkey, Seamus Hegarty, and Errol Cocks, who reviewed earlier versions of this manuscript. 


\section{References}

Abell, S., Ashmore, J., Beart, S., Brownley, P., Butcher, A., Clarke, Z. et al. (2007). Including everyone in research: The Burton street research group. British Journal of Learning Disabilities, 35, I2I-124.

Association for Self-Advocacy, Croatia, Association for Promoting Inclusion, Croatia, and Inclusion Europe (2007). Human rights of persons with intellectual disability. Country report Republic of Croatia. Retrieved November I $5^{\text {th }} 2009$ from http://www.inclusion-europe.org/documents/HR-FinalReport-EN-web.pdf.

Barnes, C. (2006). "What a difference a decade makes: reflections on doing 'emancipatory disability research'.” In L. Barton (Ed.) Overcoming disabling barriers, Pp. 346-36I. Oxon: Routledge.

Barton, L. (2005). Emancipatory research and disabled people: some observations and questions. Educational Review, 57(3), 317-327.

Bigby, C. \& Frawley, P. (20I0). Reflections on doing research in the "Making Life Good in the Community" study. Journal of Intellectual \& Developmental Disability, 35, 53-6I.

Clifford, J. (20II). The UN Disability Convention and its Impact on European Equality Law, The Equal Rights Review, 6, II-25.

Curtice, L. (2006). How is it going?: A survey of what matters most to people with learning

disabilities in Scotland today. Retrieved November I5th 20II from http://www.scld.org.uk/library-publications/how-it-going-a-survey-what-mattersmost-people-with-learning-disabilities-scotl.

Dowse, L. (2009). 'It's like being in a zoo': Researching with people with intellectual disability. Journal of Research in special Educational Needs, 93, I 4I-I 53.

Emerson, E., Malam, S., Davies, I., \& Spencer, K. (2005). Adults with Learning Difficulties in England 2003/4: Full report. Retrieved November $15^{\text {th }} 201 \mathrm{I}$ from http://www.lancs.ac.uk/staff/emersone/FASSWeb/Emerson 05 ALDE_Main.pdf.

Garbutt R., Tattersall, J., Dunn, J., \& Boycott-Garnett, R. (2009). Accessible article: involving people with learning disabilities in research. British Journal of Learning Disabilities, 38, $21-34$.

Gilbert, T. (2004). Involving people with learning disabilities in research. Health and Social Care in the Community, I24, 298-308.

Goodley, D. \& Moore, M. (2000). Doing disability research: activist lives and the academy. Disability and Society, I56, 86I-882.

Healy, E., McGuire, B.E., Evans, D.S., \& Carley, S.N. (2009). Sexuality and personal relationships for people with an intellectual disability. Part I: service-user perspectives. Journal of Intellectual Disability Research, 53, 905-912.

Hegarty, S. (1997). Educational research in context. In S. Hegarty (Ed.), The Role of Research in Mature Education Systems. Slough: NFER.

Inclusive Research Network (IRN). (2009). Where we live: A national study done by members of the Inclusive Research Network through surveys. Dublin: National Institute for Intellectual Disability Ireland; Galway: National Federation of Voluntary Bodies. Retrieved November $15^{\text {th }} 201$ I from http://www.tcd.ie/niid/pdf//RN\%20revised\%20folder/PDFs/Where\%20we\%20Live\%2 OReport\%2020 I0.pdf. 
Inclusive Research Network (IRN). (2010). Relationships and Supports Study: People with Intellectual Disabilities in Ireland. Dublin: National Institute for Intellectual Disability Ireland; Galway: National Federation of Voluntary Bodies. Retrieved November $15^{\text {th }} 20$ I I from http://www.tcd.ie/niid/pdf/IRN\%20revised\%20folder/ PDFs/ Relationships\%20and\%20Supports\%20Report\%202010.pdf.

Johnson, K. (2009). No Longer Researching About Us Without Us: a researcher's reflection on rights and inclusive research in Ireland. British Journal of Learning Disabilities, 37, 250-256.

Kellett, M. (2010). We Can 2: exploring the implications of young people with learning disabilities engaging in their own research. European Journal of Special Needs Education, 25I, 3I-44.

Kelly, G., Crowley, H., \& Hamilton, C. (2009). Rights, sexuality and relationships in Ireland: 'It'd be nice to be kind of trusted'. British Journal of Learning Disabilities, 37, 308-3 I 5.

Kramer, J.M., Kramer, J.C., García-Iriarte, E., \& Hammel, J. (20I I). Following through to the end: The use of inclusive strategies to analyse and interpret data in participatory action research with individuals with intellectual disabilities. Journal of Applied Research in Intellectual Disabilities, 24(3), 263-273.

Logan, R., Fougere, G., Hague, K., Holloway, L., Kiro, C., Moore, A., et al. (2003). To have an 'ordinary' life. Report to the Minister of Health and the Minister for Disability Issues from the National Advisory Committee on Health and Disability (New Zealand). Retrieved November $15^{\text {th }} 201$ I from http://www.nhc.health.govt.nz /resources/publications/have-ordinary-life-kia-whai-oranga-noa.

McBeth, J.L. (2010). Reflecting on disability research in sport and leisure settings. Leisure studies, 29 (4), 477-485.

National Disability Authority (NDA). (2004). Survey on Social Participation and Disability. Retrieved November I $5^{\text {th }} 201$ I from http://www.nda.ie/cntmgmtnew.nsf/0/9F I I837D4C632B62802570660054EC I I?Op enDocument.

National Disability Authority (NDA). (2009). Ethical Guidance for Research with People with Disabilities. Retrieved June 20th from http://www.nda.ie/cntmgmtnew.nsf/0/232F6 I AE5397A93D802576650052B3B9/\$Fil e/ethicsfootnotes.html.National Federation of Voluntary Bodies (2007). People connecting. Retrieved November I $5^{\text {th }} 201 \mathrm{I}$ from http://www.fedvol.ie/_fileupload/People\%20Connecting\%20-\%20June\%202007.pdf.

National Institute for Intellectual Disability (NIID). (2009). All We Want to Say: People with Intellectual Disabilities Presenting Research Findings in Ireland. Dublin: Trinity College Dublin. Retrieved November $15^{\text {th }} 201$ I from http://www.tcd.ie/niid/pdf/IRN\%20revised\%20folder/PDFs/All\%20We\%20Want\%20t o\%20Say\%20Report\%202009.pdf.

National Institute for Intellectual Disability (NIID). (2010). All we want to say: Life in Ireland for people with intellectual disabilities. Dublin: Trinity College Dublin. Retrieved November $15^{\text {th }} 20 \mathrm{II}$ from http://www.tcd.ie/niid/pdf/IRN\%20revised\%20folder/PDFs/All\%20We\%20Want\%20t o\%20Say\%20Report\%202010.pdf.

Oliver, M. (1992). Changing the social relations of research production? Disability and Society, 7, I0I-II4.

Priestley, M., Waddington, L., \& Bessozi, C. (2010). Towards an agenda for 
disability research in Europe: learning from disabled people's organizations.

Disability and Society, 25 (6), 731-746.

Townsend, C. (20II). Developing a comprehensive research agenda for people with intellectual disability to inform policy development and reform. Journal of Policy and Practice in Intellectual Disabilities, 8(2), II 3-1 24.

Tuffrey-Wijne, I. \& Butler, G. (2009). Co-researching with people with learning disabilities: an experience of involvement in qualitative data analysis. Health Expectation, I3, 174- 184.

Turnbull, H. \& Turnbull, A.P. (1994). Participatory action research and public policy. Retrieved November $15^{\text {th }} 201$ I from http://eric.ed.gov/PDFS/ED344358.pdf.

United Nations. Convention on the Rights of Persons with Disabilities (2006).

United Nations. Convention and Optional Protocol Signatories and Ratifications. Convention on the Rights of Persons with Disabilities. Retrieved June $25^{\text {th }} 2012$ from http://www.un.org/disabilities/countries.asp?navid= I 2\&pid= 166.

Walmsley, J. (200I). Normalisation, emancipatory research and inclusive research in learning disability. Disability and Society, 167, 187-205.

Walmsley J. \& Johnson, K. (2003). Inclusive Research with People with Learning Disabilities: Past, Present and Futures. London: Jessica Kingsley Publishers.

Ward, L., \& Townsley, R. (2005). 'It's about dialogue...' Working with people with learning difficulties to develop accessible information. British Journal of Learning Disabilities, 33(2), 59-64.

Wyre Forest Self-Advocacy \& Tarleton, B. (2005). Writing it ourselves. British Journal of Learning Disabilities, 33, 65-69.

Zarb, G. (1992). On the road to Damascus: First steps towards changing the relations of disability research production. Disability and Society, 7, I25-I38. 